\title{
Evaluation of Radiation Consequences of Releases in Accidents with Spills of Liquid Radioactive Materials in Areas with Forced Ventilation
}

\author{
Oleksandra Slepchenko, Volodymyr Bogorad, Yurii Kyrylenko* \\ State Scientific and Technical Center for Nuclear and Radiation Safety, Ukraine
}

Copyright $(2016$ by authors, all rights reserved. Authors agree that this article remains permanently open access under the terms of the Creative Commons Attribution License 4.0 International License

\begin{abstract}
This report focuses on assessment of radiation consequences of releases in accidents with spills of liquid radioactive materials in areas with forced ventilation. During the study, characteristic dependences between parameters of liquid radioactive materials and air exchange in areas with forced ventilation and associated radiation consequences were determined. The proposed approach is based on the theory of non-stationary heat and mass transfer in surface evaporation of liquid heated below the boiling temperature. The physical model includes: liquid radioactive material, steam-aerosol radioactive mixture, air of forced ventilation, airborne filters, and floor of the emergency area. The key aspects of the model are evaporation of liquid material, its removal with exhaust ventilation and partial trapping on airborne filters. It is considered that the steam-aerosol radioactive mixture is released to the environment after filters. The advantage of this model is the possibility to determine integral release of radionuclides to the environment and activity concentration of air in the emergency area at any moment after beginning of the accident, effective dose received by an adult during 14 days for a wide range of input thermodynamic and geometrical parameters, different operating modes of the ventilation system and different productivities of the filtering system. Results from assessment of radiation consequences for the selected accident are presented and the associated effect of filtering systems is analyzed.
\end{abstract}

Keywords Liquid Radioactive Materials, Radiation Consequences

\section{Introduction}

Nowadays, one of the priorities in nuclear industry is to minimize actual radiation exposure on the population during normal operation of the facilities as well as potential one in case accidents. In case of an accident, the minimization is based on the dependence of radiation consequences on parameters that caused them. Such minimization is performed through analysis of the physical foundations incorporated in accident scenarios and identification of the main factors influencing their radiation consequences.

This work is devoted to the class of accidents involving spills of liquid radioactive materials (LRM) in areas with forced ventilation, assessment of activity and power of releases as well as assessment of the radiation consequences of such releases.

Worldwide there have been more than 22 significant accidents with spills of liquid radioactive materials at nuclear fuel cycle facilities for the last 60 years according to KPI's conference proceedings [1]. Among there is the accident at research reactors, nuclear power plants, nuclear complexes, pilot plants and chemical plants.

Many special computer codes and methods are currently developed to assess, with sufficient accuracy, parameters of releases for various accidents at nuclear fuel cycle facilities (e.g. MELCOR computer code manual, US NRC [2] for NPP). But, these codes often require a large amount of input data and calculation time. The advantage of the approach developed in this paper is rapid assessment of radiation consequences.

\section{LRM as an Object of Study}

LRM are liquid solutions, which include impurities of radioactive elements (possibly bound in high-molecular complexes). The isotopic composition of LRM is determined primarily by the source of radioactive impurities.

The main sources of LRM at nuclear power plants and nuclear complexes are as follows:

- primary coolant that is discharged for operational reasons;

- water that is used to back flush filters and ion exchangers; 
- floor drains that collect water that has leaked from the active liquid systems and fluids from the decontamination of the plant and fuel flasks;

- leaks of secondary coolant;

- laundries and changing room showers;

- and chemistry laboratories.

At nuclear power plants and nuclear complexes, LRM are mainly aqueous solutions of decay products of nuclear fuel according to IAEA safety standards [3] and FSUE's materials [4].

Pilot plants and chemical plants may contain a full range of isotopes and solvents.

\section{Model Overview}

The proposed approach is based on the theory of non-stationary heat and mass transfer in surface evaporation of liquid heated below the boiling temperature. The physical model includes: active liquid medium, steam-aerosol radioactive mixture (SARM), air of forced ventilation, airborne filters, and the floor of emergency area. The key aspects of the model are evaporation of liquid material, its removal with exhaust ventilation and partial trapping on airborne filters. It is considered that SARM is released to the environment after filters.

The model is developed to assess the radiation consequences in an accident with spill of LRM and describes the spread of radioactive material by two consecutive ways: releases within the emergency area and further transfer of SARM into the atmosphere. In this paper, we focus on the relationship of these pathways and study the process of evaporation as special one for accident with spill of LRM.

\subsection{Basic Principles and Assumptions of the Model}

The model of LRM evaporation describes the transport of radionuclides within the emergency area. It takes into account processes such as:

- evaporation of the radioactive material;

- $\quad$ drainage of LRM;

- cooling of LRM by evaporation and heat transfer from floor;

- entrainment of SARM via ventilation;

- cleaning of SARM to remove radioactive aerosols on the filtration facility;

- release of LRM to the atmosphere.

Key assumptions in modeling the thermal evaporation processes:

- temperature of LRM is always higher than the temperature of involved air;

- condensation of SARM on surfaces of equipment and building designs is neglected;

- $\quad$ pressure in the airspace of the area is constant and equals atmospheric pressure;

- LRM's heat transfer coefficient relative to the floor does not depend on LRM temperature;
- convection flows within LRM are absent;

- concentration gradient of radionuclides in LRM is absent;

- heat transfer through the evaporation surface to the air of ventilation is neglected;

- velocity fields of aerodynamic flow and thermodynamic parameters of the air over the entire surface of evaporation are constant.

\subsection{Description of LRM Evaporation}

The process of evaporation that occurs in direct contact of the supplied air and liquid surface is complex. It combines the effects of heat and mass transfer. The mass flow of SARM released from the surface of the liquid is determined by the Dalton equation according to Nesterenko [5]:

$$
d m_{w}=-\beta_{s w} \cdot\left(p_{s w}-p_{m}\right) \cdot S d t
$$

where $m_{w}$ - mass of LRM, $k g$;

$\beta_{s w}-$ mass transfer coefficient for normal atmospheric pressure, $\frac{\mathrm{kg}}{\mathrm{Pa} \cdot \mathrm{m}^{2} \cdot \mathrm{s}}$

$p_{s w}, p_{m}$-saturation pressures of LRM for temperature of liquid surface $T_{s w}$ and temperature of involved air $T_{m}$ (Fig.1), $P a$;

$S$ - area of evaporation surface, $m^{2}$; $t$-time, $s$.

Accordingly, the heat flow which is directed from the liquid to the supplied air is:

$$
d Q_{e v}=-r_{w} \cdot \beta_{s w} \cdot\left(p_{s w}-p_{m}\right) \cdot S d t
$$

where $r_{w}$ - heat of LRM evaporation, $J / k g$

In this case, if the temperature of LRM is always higher than the temperature of the supplied ventilation air in the boundary liquid layer, it gives rise to the temperature gradient, the nature of which depends on the intensity of heat and mass transfer.
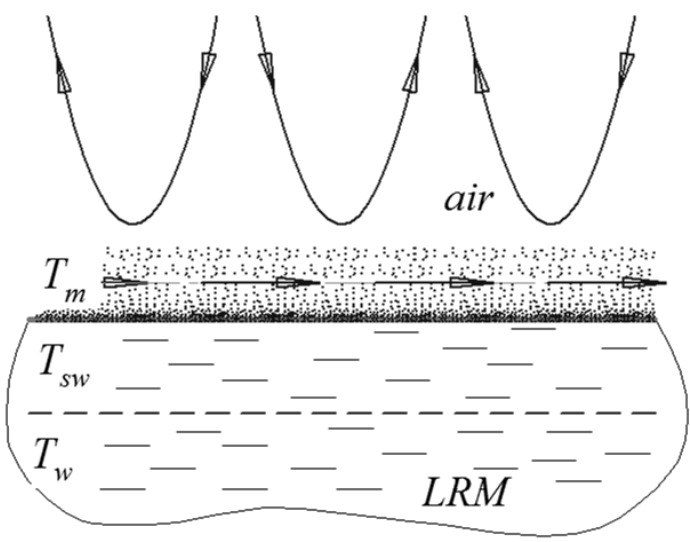

Figure 1. The temperature gradient on the surface of LRM

The experimental data [6] show that the intensity of water 
transfer during evaporation depends on hygrothermal state of the incoming air flow (Fig. 1).

On the basis of experimental studies [5], [6], the dependence of surface temperature of the evaporating liquid on hygrometric conditions and hydrodynamic process when the heat flow is directed from liquid surface to the environment was established. According to formulas (1) and (2), the parameters $\beta_{s w}$ and $p_{s w}$ are functions of temperature of the liquid surface $T_{s w}$, and value $r_{w}$ is functions of temperature within the liquid $T_{w}$.

The model of evaporation also describes the heat transfer from liquid to the floor of emergency area. According to Isachenko [7], the heat transfer from the liquid to the floor is described by the expression:

$$
d Q_{f}=k \cdot F \cdot\left(T_{w}-T_{f}\right) d t
$$

where $k$ - heat transfer coefficient for floor (this value can be found according to Isachenko [7]), $\frac{W}{m^{2} \cdot K}$;

$F$ - area of contact surface of LRM with the floor, $\mathrm{m}^{3}$.

Then the heat balance for LRM can be written as

$$
d Q_{w}=-d Q_{e v}-d Q_{f}
$$

At the same time

$$
d Q_{w}=c_{p} m_{w} d T_{w}
$$

where $c_{p}$ - isobaric heat capacity of LRM (value $c_{p}$ is function of temperature $\left.T_{w}\right), \frac{\mathrm{J}}{\mathrm{kg} \cdot \mathrm{K}}$

In view of formulas (2), (3) and (5), heat balance for LRM (4) can be written as

$$
c_{p} m_{w} d T_{w}=-r_{w} \beta_{s w}\left(p_{s w}-p_{m}\right) S d t-k F\left(T_{w}-T_{f}\right) d t
$$

Functions $\beta_{s w}\left(T_{s w}\right), p_{s w}\left(T_{s w}\right), p_{m}\left(T_{m}\right), r_{w}\left(T_{w}\right)$ and $c_{p}\left(T_{w}\right)$ are polynomials. They are compiled according to Volkov [8] and Rivkin \& Aleksandrov [9].

In model, the performance of forced ventilation unit is determined by the flowrate of involved air. After the exhaust ventilation pipe, SARM partially settles on filters. This phenomenon accounts for the coefficient of filtration. It determines the relative amount of SARM that is deposited on the filter material. SARM further passes through the ventilation stack into the atmosphere.

Another method to confine LRM is to drain the spilled liquid by drainage pumps or by gravity. This process is characterized by the flowrate of LRM through the drainage channel.

The partial removal of radioactive substances from the liquid by evaporation depends on physicochemical properties of radioactive impurities and the solvent.

\subsection{Modeling of the LRM Evaporation}

To solve the problem of unsteady LRM evaporation, using equations (1)-(6), four balance differential equations (7) were written to relate the main parameters of LRM and air space of area over time.

$$
\left\{\begin{array}{l}
\frac{d m_{w}}{d t}=-\beta_{s w}\left(p_{s w}-p_{m}\right) S-G_{d} \\
\frac{d m_{a}}{d t}=\beta_{s w}\left(p_{s w}-p_{m}\right) S-G_{V} \cdot \frac{m_{a}}{V} \\
\frac{d m_{q}}{d t}=G_{V} \frac{m_{a}}{V}(1-\psi) \\
\frac{d T_{w}}{d t}=-\frac{r_{w} \beta_{s w}\left(p_{s w}-p_{m}\right) S+k F\left(T_{w}-T_{f}\right)}{c_{p} m_{w}}
\end{array}\right.
$$

where $m_{a}-$ current mass of SARM in air of the area, $\mathrm{kg}$;

$G_{d}$ - flowrate of LRM through the drainage channel (it also includes the volume of LRM leakage from the area), $\mathrm{kg} / \mathrm{s}$

$V$-air volume in the area, $m^{3}$;

$G_{V}$ - flowrate of involved air of forced ventilation (this parameter includes SARM leakage through the gaps or clearances in walls of the emergency area) $\mathrm{m}^{3} / \mathrm{s}$;

$\psi$ - coefficient of filtration (efficiency of filtration);

$m_{q}$-mass of released SARM into the atmosphere, $\mathrm{kg}$

This system of nonlinear differential equations includes polynomial functions. Using the Mathcad sphere for solving the system of equations (7) provides the desired functions in matrix form (the values of the functions at particular moments of accident).

Average activity concentration of the radionuclide in the area air $A_{\text {air }}\left(B q / \mathrm{m}^{3}\right)$ is given by the formula

$$
A_{\text {air }}=\frac{A_{w}}{V} H \cdot m_{a}
$$

where $A_{w}$ - concentration of radionuclide in LRM, $B q / \mathrm{kg}$;

$\mathrm{H}$-fraction of carried away solute with solvent vapors during evaporation.

The ultimate objective of the model is to determine the dynamics of LRM evaporation, SARM activity in the air space and the integral release of radioactive substances into the atmosphere. The mass fraction of a radionuclide in the release relative to its original content in radioactive liquid is commonly used in practice:

$$
q=\frac{A_{w}}{m_{0}} H \cdot m_{q} \cdot 100 \%
$$

where $m_{0}$-initial mass of LRM, $\mathrm{kg}$

This value is used as an input parameter for the assessment of doses to the population from atmospheric release. 


\subsection{Description of SARM Atmospheric Transport}

There are a considerable number of theoretical and experimental studies devoted to the dispersion of pollutants released into the atmosphere. Simplified approaches may be used in calculations for dispersion modeling. One of such approaches is the Pasquill-Gifford method described by Gusev \& Belyaev [10]. The calculation with this method involves selecting conservative categories of atmospheric stability and wind speed depending on the effective height of SARM release. These parameters are crucial in the distribution of radioactive substances in the territory surrounding the emergency facilities.

Using method the Pasquill-Gifford method, we find fields of volume activity concentration in air and surface activity concentration on the ground of radionuclides. These parameters define the effective doses to the public.

\subsection{Assessment of Effective Dose}

The effective dose includes 3 special effective doses. It finds as

$$
D_{e f}=\sum_{i}\left(D_{i}^{a i r}+D_{i}^{s r f}+D_{i}^{i n g}\right)
$$

where $D_{i}^{\text {air }}$ - effective dose due to inhalation and external irradiation from cloud (for $i$-th radionuclide), $S v$

$D_{i}^{s r f}$ - effective dose due to external irradiation from ground surface(for $i$-th radionuclide), $S v$

$D_{i}^{\text {ing }}$ - effective dose due to ingestion (for $i$-th radionuclide), $S v$

Assessment of effective dose during 14 days received by an adult $D_{e f}$ is based on the method according Ukrainian standards [11].

\subsection{Results of Assessment of Radiation Consequences}

The assessment resulted in a series of basic parameters of the radiation environment within and outside the emergency area:

- average activity concentration of the radionuclide in the area air $A_{\text {air }}$,

- mass fraction of the radionuclide in the release relative to the original content in radioactive liquid $q$,

- $\quad$ effective dose received by an adult during 14 days as a result of SARM release $D_{e f}$.

\section{Analysis of the Influence of Initial Accident Conditions on the Results of Assessment}

During the study, we assessed radiation consequences with the aim of briefly analysis of some results obtained for the hypothetical accident with spills of LRM in the storage area of liquid radioactive waste with a forced ventilation system, according to the input data specified in Table. 1.

Table 1. Input data of assessment

\begin{tabular}{|c|c|c|}
\hline No & Parameter & Value \\
\hline 1 & Initial mass of LRM $m_{0}, k g$ & $\begin{array}{c}2.0 \\
10^{5}\end{array}$ \\
\hline 2 & Initial temperature of LRM $T_{w 0},{ }^{\circ} C$ & 98 \\
\hline 3 & Area of evaporation $S, m^{2}$ & 200 \\
\hline 4 & Area of contact surface of LRM with the floor $F, m^{2}$ & 210 \\
\hline 5 & Average temperature of the floor $T_{f},{ }^{\circ} C$ & 20 \\
\hline 6 & Air volume in the area $V, m^{3}$ & 1000 \\
\hline 7 & Efficiency of filtration $\psi$ & 0 \\
\hline 8 & Heat transfer coefficient for the floor $k^{*}, \quad \frac{W}{m^{2} \cdot K}$ & 15.4 \\
\hline 9 & Average activity concentration of radionuclide in & 3.7. \\
& LRM $A_{w}, B q / k g:$ & $10^{8}$ \\
${ }^{137} \mathrm{Cs}$ & 4.7 \\
& ${ }^{60} \mathrm{Co}$ & $10^{7}$ \\
\hline
\end{tabular}

*It was found for layered floor according to Isachenko [7]: the outer layer polymer $(2 \mathrm{~mm})$, the inner layer - concrete $(1 \mathrm{~m})$

SARM released into the atmosphere through the ventilation stack (100 $\mathrm{m}$ height) in the following weather conditions:

- $\quad$ wind speed of $1 \mathrm{~m} / \mathrm{s}$;

- $\quad$ class of atmospheric stability "B" (the most conservative class for release height of $100 \mathrm{~m}$ ); roughness of the underlying surface soil $-10 \mathrm{~cm}$

To analyze the influence of the initial accident conditions on the final results of the assessment, a number of input parameters were chosen: flowrate $\left(G_{V}\right)$ and temperature $\left(T_{m}\right)$ of supplied ventilation air, LRM drainage flowrate $\left(G_{d}\right)$. Unlike other parameters, these values can be adjusted during an accident. These data are represented as a series of values in Table 2.

Table 2. Input parameters of operating modes of ventilation and drainage systems

\begin{tabular}{|c|c|c|c|}
\hline No & $G_{V}, m^{3} / s$ & $T_{m},{ }^{0} C$ & $G_{d}, \mathrm{~kg} / \mathrm{s}$ \\
\hline 1 & 0.001 & \multirow{4}{*}{10} & \multirow{4}{*}{0} \\
\hline 2 & 0.75 & & \\
\hline 3 & 1.5 & & \\
\hline 4 & 2.25 & & \\
\hline 5 & \multirow{3}{*}{0.75} & 5 & \multirow{3}{*}{0} \\
\hline 6 & & 25 & \\
\hline 7 & & 45 & \\
\hline 8 & \multirow{4}{*}{0.75} & \multirow{4}{*}{10} & 0 \\
\hline 9 & & & 50 \\
\hline 10 & & & 100 \\
\hline 11 & & & 150 \\
\hline
\end{tabular}

\subsection{Results of Assessment}

Some results of the assessment of radiation consequences are shown in Table 3 (for the mix ${ }^{137} \mathrm{Cs}+{ }^{60} \mathrm{Co}$ ) and Figs. 2-4 (only for ${ }^{137} \mathrm{Cs}$ ).

Curves of Figs. 2-4 for ${ }^{137} \mathrm{Cs}$ are similar to ${ }^{60} \mathrm{Co}$, cause, according to formula (8), the values of activity concentration $A_{\text {air }}$ of both radionuclide's are linearly dependent. According to formula (9), it is the same for mass fraction $q$. Therefore, 
for the analysis we showed the curves only for ${ }^{137} \mathrm{Cs}$.

Table 3. Values of the maximum effective dose to the human body during 14 days depending on the operating modes of ventilation and drainage systems

\begin{tabular}{|c|c|}
\hline No & Effective dose $\boldsymbol{D}_{\boldsymbol{e f}}, \boldsymbol{\mu S v}$ \\
\hline 1 & 1.94 \\
\hline 2 & 14.90 \\
\hline 3 & 15.53 \\
\hline 4 & 16.15 \\
\hline 5 & 16.50 \\
\hline 6 & 15.53 \\
\hline 7 & 12.53 \\
\hline 8 & 14.83 \\
\hline 9 & 3.13 \\
\hline 10 & 1.88 \\
\hline 11 & 1.39 \\
\hline
\end{tabular}

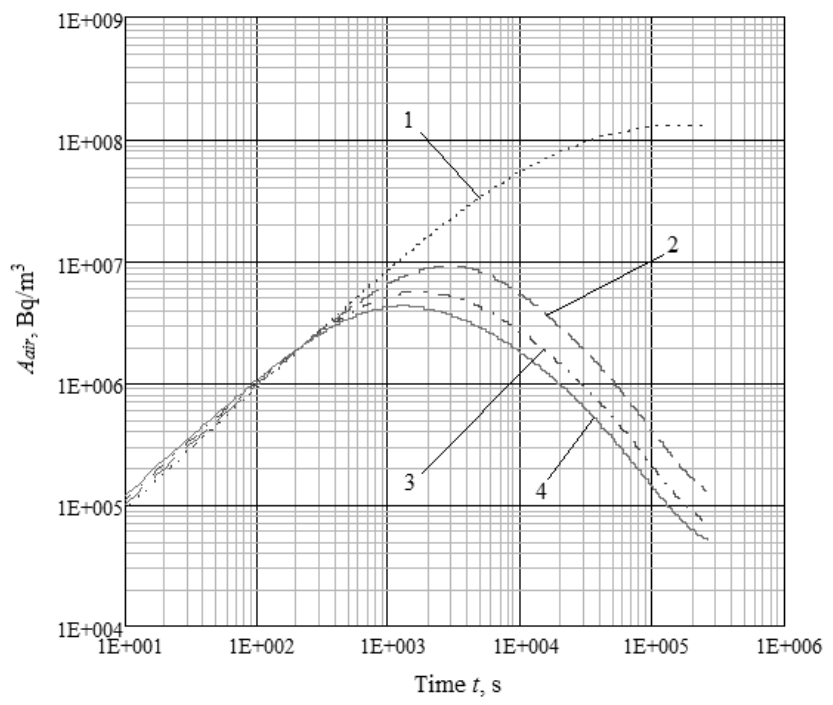

a)

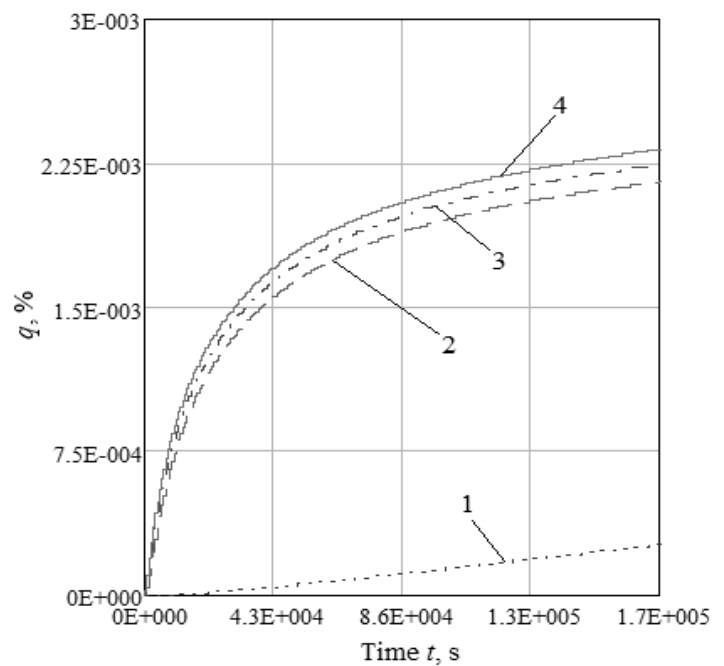

b)

Figure 2. Changes in average activity concentration in the air of emergency area (a) and mass fraction of ${ }^{137} \mathrm{Cs}$ released to the environment (b) for the following ventilation flow rates: $G_{V}=0.001 \mathrm{~m}^{3} / \mathrm{s}$ (curve 1); $G_{V}=0.75$ $\mathrm{m}^{3} / \mathrm{s}$ (curve 2); $G_{V}=1.5 \mathrm{~m}^{3} / \mathrm{s}$ (curve 3 ); $G_{V}=2.25 \mathrm{~m}^{3} / \mathrm{s}$ (curve 4)

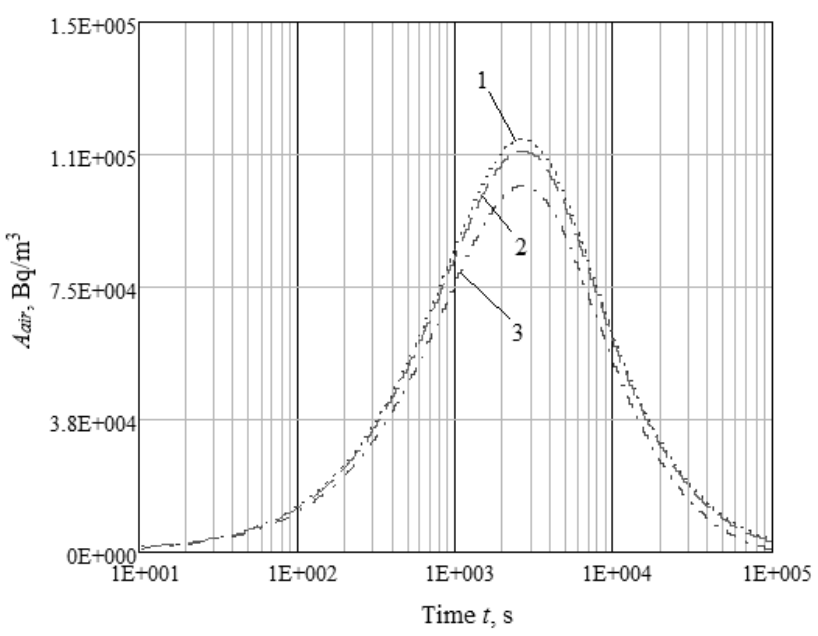

a)

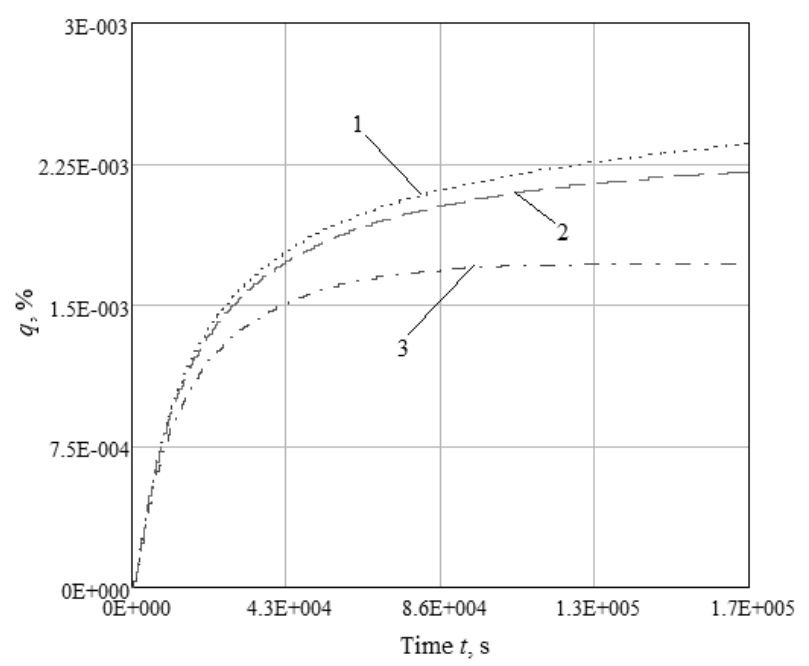

b)

Figure 3. Changes in average activity concentration in the air of emergency area (a) and mass fraction of ${ }^{137} \mathrm{Cs}$ released to the environment (b) for the following supply air temperature: $T_{m}=5^{\circ} \mathrm{C}$ (curve 1), $T_{m}=25^{\circ} \mathrm{C}$ (curve 2), $T_{m}=45^{\circ} \mathrm{C}$ (curve 3 )

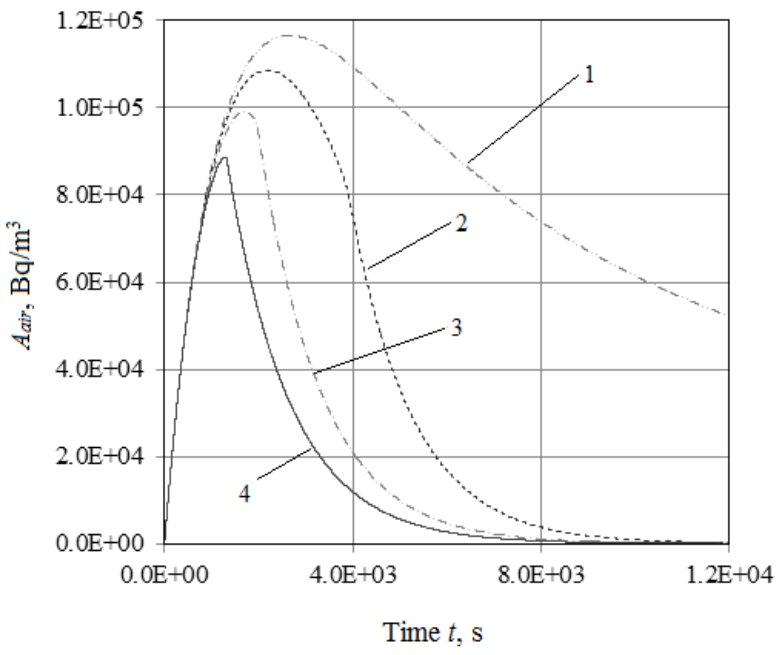

a) 


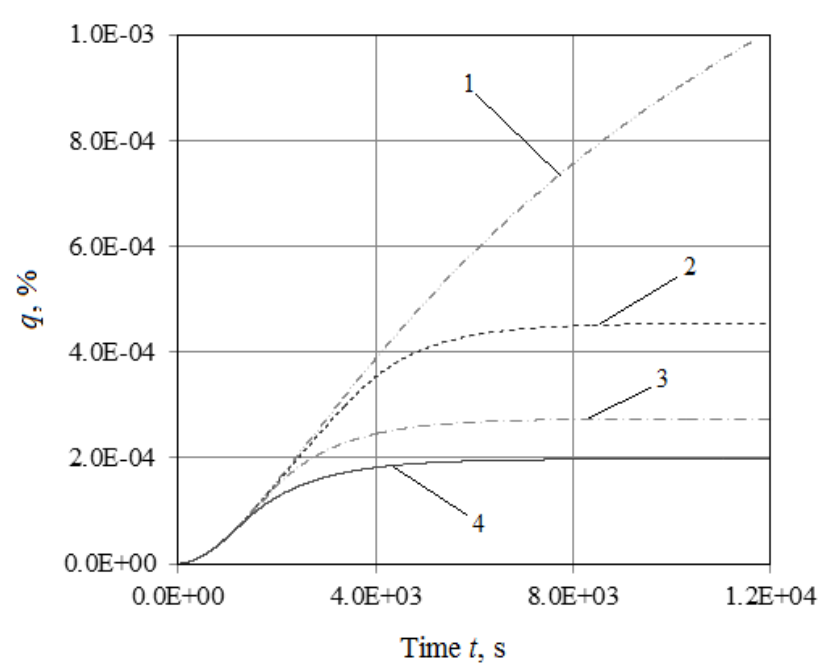

b)

Figure 4. Changes in average activity concentration in the air of emergency area (a) and mass fraction of ${ }^{137} \mathrm{Cs}$ released to the environment (b) for the following drainage flow rates: $G_{d}=0 \mathrm{~kg} / \mathrm{s}$ (curve 1), $G_{d}=50 \mathrm{~kg} / \mathrm{s}$ (curve 2), $G_{d}=100 \mathrm{~kg} / \mathrm{s}$ (curve 3), $G_{d}=150 \mathrm{~kg} / \mathrm{s}$ (curve 4)

\subsection{Analysis}

According to the assessment results (Fig. 2a), with higher flow rate, the activity concentration in the air of emergency area reduces and the release of radionuclides into the atmosphere (Fig. 2b) slightly increases with further growth of the flow rate. Therefore, there is the minimum flow rate that may provide sufficient reduction in SARM activity in the air of area. In this accident, atmospheric release is eliminated only if the ventilation system is inactive and the emergency area is completely confined.

The results presented in Fig. 3 indicate that heating of supply ventilation air (to the temperature of LRM surface $T_{s w}$ ) helps to suppress the evaporation process. The activity concentration of SARM in the air of emergency area and integral SARM release into the atmosphere decrease with increasing temperature of supply air.

The calculated data show (Fig. 4) that drainage of LRM is the most effective way to confine and prevent the release of radioactive substances into the air of emergency area and the environment. In the absence of drainage (curve 1, Fig. 4b), the integral release of SARM is rapidly growing even in 2 hours from the beginning of the accident.

It is interesting to note that curves $2-4$ in Fig. $4 \mathrm{a}$ are not smooth. Each of them has the point of "breaking". At these times, the confinement of LRM and the evaporation process are terminated. Clearing of SARM remaining in the air of area begins.

In all cases, the effective dose to the public and personnel from a particular radionuclide is directly proportional to the size of release and activity concentration in the emergency area, respectively. Assessment of effective doses to the public has showed that this accident cannot cause significant radiation consequences (Table 3 ). High flow rate and low temperature of supplied ventilation air contribute to increase effective doses to the public.

\section{Conclusions}

The developed model can be used directly during an accident and with a reasonable degree of conservatism to give an adequate assessment of the radiation consequences for the set of initial conditions of accidents with spills of LRM in areas with forced ventilation.

During the study, characteristic dependences between parameters of liquid radioactive materials and air exchange in areas with forced ventilation and associated radiation consequences for the public were determined. The analysis of the influence of initial accident conditions on the results of assessment showed that there is a minimum set of countermeasures and facilities that can significantly reduce the radiation consequences of accidents with spills of LRM in areas with forced ventilation system, thereby reducing the dose to the public and facility personnel. Thus, in case of an accident with leakage of a radioactive water solution with a temperature close to the boiling point, rapid drainage of LRM and ventilation of the emergency area with heated air can ensure the minimum activity concentration of SARM within the area and the release of radioactive substances into the environment.

\section{REFERENCES}

[1] The XIII Scientific and Practical Conference "Modern problems of scientific power ware" of Post graduate Students, Masters of Arts and Students. National Technical University of Ukraine "Kyiv Polytechnic Institute" 21-24.04.2015.

[2] MELCOR Computer Code Manuals. Office of Nuclear Regulatory Research U.S. Nuclear Regulatory Commission Washington, NUREG/CR-6119, Vol. 3.

[3] IAEA safety standards series. Radiation protection aspects of design for nuclear power plants. NoNS-G-1.13, IAEA, Vienna, 2005.

[4] Materials on environmental impact assessment of the proposed activity on the operation of a nuclear facility, a complex of nuclear materials intended for radiochemical reprocessing of spent nuclear fuel. Federal State Unitary Enterprise "Production Association "Mayak" FSUE" PA "Mayak", 2012.

[5] NESTERENKO, Aleksey V. Fundamentals of thermodynamic calculations ventilation and air conditioning. Moscow: Vysshaia Shkola, 1971. 460p.

[6] NESTERENKO, Aleksey V. Experimental study of heat and mass transfer during evaporation of the liquid with a free surface. Material science. Technical Physics. Academy of Sciences of the USSR. Vol. 24, No. 4, 1954.

[7] ISACHENKO, Victor P, OSIPOVA, Varvara A., SUKOMEL, Aleksandr S. Heat transfer. Moscow: Energiya, 1975. 488 p.

[8] VOLKOV, Oleg D. Designing of industrial building ventilation. Kharkov: Vyscha Shkola, 1989. 240p. ISBN 5-11-000656-3. 
[9] RIVKIN, Solomon L., ALEKSANDROV, Aleksey A.
Thermodynamic properties of water and steam. Directory .Moscow: Energiya, 1984. 80 p.

[10] GUSEV, Nicolay G., BELYAEV, Valentin A..Radioactive releases in the biosphere. Moscow: Energoatomizdat, 1991. 256p. ISBN 5-283-03025-3.
[11] Standard of National Nuclear Energy Generating Company "Energoatom".Procedure for setting the size of the sanitary protection zone NPP, 2014. 